\title{
Crecimiento económico, información asimétrica en mercados financieros $y$ microcréditos
}

\author{
Horacio Esquivel-MartíneZ* \\ Ulises HernáNDEZ-Ramos***
}

\begin{abstract}
This paper presents a theoretical study about the relationship between the development of financial institutions, the decrease of asymmetric information and its impact on economic growth. Through the analysis of the Solow model of economic growth and the theory of asymmetric information and its consequences, i.e. adverse selection, moral hazard and credit rationing by Stiglitz and Weiss, we conclude that the development of a financial system has a high incidence on economic growth as pointed out by other authors such Mackinnon and Levine.
\end{abstract}

Key words: microcredits, economic growth, asymmetric information, adverse selection, moral hazard, credit rationing.

\section{Resumen}

Se presenta un artículo teórico respecto a la relación existente entre desarrollo de instituciones financieras, reducción de la información asimétrica y su impacto en el crecimiento económico. Mediante el análisis del modelo de Solow sobre la teoría del crecimiento económico y la teoría de la información asimétrica y sus consecuencias: selección adversa, riesgo moral y racionamiento de crédito de Stiglitz y Weiss, se concluye que el desarrollo del sistema financiero tiene una alta incidencia en el crecimiento económico, como señalan autores como Mackinnon y Levine.

Palabras clave: microcrédito, crecimiento económico, información asimétrica, selección adversa, riesgo moral, racionamiento de crédito.

\footnotetext{
* Universidad Nacional Autónoma de México y Southern New Hampshire University. Correo-e:horaesquivel@gmail.com

**El Colegio de México. Correo-e: uliseshr2000@yahoo.com.mx.
} 


\section{Prolegómeno ${ }^{1}$}

En el contexto de la teoría del crecimiento, el enfoque neoclásico, al igual que la teoría evolucionista subraya el papel del progreso técnico en el crecimiento económico. Esta última destaca el papel de la demanda en el crecimiento. Antes de la crisis fiscal del Estado (Robinson, 2001), las políticas ponían especial énfasis en el gasto de gobierno, comúnmente en forma de subsidio y transferencia directa. Esta forma de utilizar el gasto se hacia mediante la banca de desarrollo, cuyos recursos se destinaban a distintos proyectos sin que existiera una genuina preocupación por recuperarlos (Hernández Trillo, 2003).

Actualmente, se postula que una forma posible de ejercer el gasto, y en particular el gasto social, es por medio de instituciones microfinancieras de acuerdo con el esquema de microcrédito, para que mediante su uso se alivien las caídas en los ciclos económicos (Mansell, 1995; Esquivel, 2006b).

Esta afirmación se sustenta en el hecho de que durante los últimos siete años, las instituciones auxiliares de crédito, arrendadoras financieras, sociedades de ahorro y préstamo, uniones de crédito y, principalmente, las cajas de ahorro y crédito popular, así como las sociedades financieras de objeto limitado (Sofoles), han experimentado en lo general un crecimiento significativo, aun cuando la crisis de 1995 generó una contracción de todo el sector financiero, especialmente en el ramo de las uniones de crédito (Ruiz Durán, 2002).

El esquema de microfinanciamiento ha crecido, pero paradójicamente, hasta el año 2000 lo hizo sin el apoyo gubernamental. ${ }^{2}$ A escala mundial, este sector se compone en su mayoría de organismos no gubernamentales (ONG), seguidos de uniones de crédito y bancos comerciales. En México, predominan las uniones de crédito, con un total de 169, seguidas de los Sofoles (34) y de las sociedades de ahorro y préstamo 11 (Ruíz-Durán, 2002).

Sin embargo, existe un número considerable de estas sociedades, mejor conocidas como cajas de ahorro, no registradas, que movilizan la mayor cantidad de ahorro del país, con 11,000

${ }^{1}$ El presente artículo se realizó a partir de un proyecto de tesis doctoral.

${ }^{2}$ A partir del año 2000, el gobierno federal puso en marcha el Programa Nacional de Financiamiento al Microempresario (Pronafim) por meido de dos fideicomisos: Fideicomiso Nacional de Financiamiento al Microempresario (Finafim) y Fondo de Microfinanciamiento a Mujeres Rurales (Fommur). Por su parte, el gobierno del Distrito Federal, inició una estrategia de otorgamiento de microcréditos por medio del Fondo de Desarrollo Social del Distrito Federal (Fondeso). 
millones de pesos, contra 3,000 millones de las uniones de crédito, 1,500 millones de pesos del Patronato del Ahorro Nacional, y sólo 1,400 millones de pesos de la banca comercial (Ruiz Durán, 2002: 33).

Los datos anteriores permiten afirmar dos cosas fundamentales: primero, que el ahorro no ha estado ligado a una política macro de ahorro, sino a factores socioculturales del ámbito local y comunitario. Segundo, que el nivel de ahorro generado por las sociedades de ahorro ha propiciado un círculo virtuoso de ahorro-crédito.

En efecto, al 2002 se tenían registrados en la cartera de crédito de estas sociedades, 8,000 millones de pesos, totalmente financiados por la propia operación institucional; es decir, se desarrolla un proceso de intermediación completa, lo que permite un crecimiento más sano de las instituciones, una política más independiente sobre el tipo de proyectos a financiar, y una menor dependencia de subsidios gubernamentales. Estos logros cobran mayor notoriedad si consideramos que las cajas de ahorro se han desarrollado sin el apoyo del prestamista de última instancia, Banco Central, cuyos esfuerzos se han canalizado a un sector bancario ineficiente y costoso.

Es necesario aclarar que en México existen pocas instituciones especializadas en microcrédito. La vasta mayoría de las mencionadas se dedican a apoyar créditos a la microempresa, con una metodología tradicional o estándar (Mansell, 1995), lo cual se distingue del microcrédito. Esto nos lleva a establecer una primera diferencia importante: no es lo mismo hablar de crédito a la microempresa que de microcrédito. El primero se enfoca al apoyo de empresas micro, formalmente establecidas, mientras que el microcrédito se enfoca a personas físicas que ejercen o inician alguna actividad productiva e incluso informal. Una segunda diferencia entre un microcrédito y un crédito al consumo consiste en el destino del crédito. Así, un crédito al consumo de una tienda comercial no es considerado un microcrédito; sí lo es, en cambio, un crédito (aun siendo del mismo monto) para emprender un pequeño negocio.

El postulado central del esquema del microcrédito consiste en financiar con ahorro las operaciones activas, lo que obliga a manejar dos elementos principales; a saber: tasas de mercado que reflejen los costos reales de financiamiento, y la recuperación de los créditos para cubrir el pasivo bancario que implica el ahorro. 
Lo anterior (Esquivel, 2006a) nos lleva a dos cuestiones fundamentales. La de las tasas de interés, que reflejan los costos de transacción de las Instituciones microfinancieras (IMF). Para reducirlas, las IMF deben esforzarse para bajar sus costos y ser más competitivas. Por su parte, las autoridades regulatorias deben fomentar condiciones de mayor competencia. Por otro lado, se pone especial énfasis no en el proyecto, sino en la recuperación de recursos por parte de las IMF, esquema que permite utilizar esos recursos en forma revolvente, con lo que se busca beneficiar a un mayor número de personas y construir instituciones autosostenibles.

Cabe mencionar que las instituciones que conforman la banca de desarrollo en México, concretamente Nacional Financiera SNC, canalizaron durante el periodo de 1988 a 1994 recursos principalmente por medio de uniones de crédito, lo que podría confundirse con el esquema aquí planteado. Los recursos que canalizaba la banca de desarrollo a través de las instituciones auxiliares y de la banca comercial, se destinaban a distintos sectores y, a diferencia de lo que plantea el microcrédito, a personas físicas y morales con reconocimiento oficial y de acuerdo con esquemas de crédito tradicionales; es decir, con garantías reales, estados financieros, avales, etcétera.

Como se ha señalado, el esquema de microcrédito plantea algo muy distinto, pues sus destinatarios son personas físicas, principalmente mujeres, que no cuentan con garantías reales, mucho menos estados financieros, y que no son sujetos de crédito para la banca comercial y los sectores tradicionales. El fundamento que subyace a este enfoque es ayudar al pobre a ayudarse a sí mismo (Conde, 2000).

El impacto que ha tenido el microcrédito ha despertado el interés del sector formal y del sistema financiero, bancos, uniones de crédito y banca de desarrollo, por atender a este segmento que se calcula mayor a los 360 millones de hogares y a 1,200 millones de personas en el mundo (Ruiz Durán, 2002). La meta pactada en la Cumbre Mundial del Microcrédito, que se llevó a cabo en febrero de 1997 en la ciudad de Washington, era alcanzar los 100 millones de familias pobres en el 2005. Sin embargo, el reto de abatir la pobreza permanece como un objetivo por cumplir. De ello se habló en noviembre del 2006, en Halifax, Nueva Escocia, en Canadá, donde se discutió el estado actual del movimiento mundial de microfinanzas en el marco de la Cumbre Mundial del Microcrédito. 


\section{Microcréditos}

La primer pregunta que debemos hacer es para qué sirven los microcréditos y cuál es el problema que atienden. Si su función es fomentar el crecimiento económico o combatir la pobreza. Algunos autores (Lacalle, 2002) sugieren que medir el impacto de los microcréditos en el crecimiento económico es difícil por dos razones: Primero, el microcrédito es una corriente relativamente novedosa; formalmente surgió en los años setenta, por lo que no se cuenta con información estadística suficiente ni en calidad ni en cantidad para medir su impacto en la macroeconomía. Segundo, los microcréditos son pequeños financiamientos que se destinan a atender a personas en grado de pobreza y pobreza extrema mediante una serie de instituciones que en su mayoría no son reguladas, lo que genera un problema de información asimétrica tanto para quien da el crédito como para quien se encarga de regular la actividad financiera en este segmento.

Así pues, al estudiar el tema del microcrédito, instituciones y beneficiarios, el principal problema con el que nos enfrentamos es el de la información. Por ello, creemos que el problema se debe estudiar desde varias perspectivas, a fin de subsanar la falta de información que se tiene por un lado, con información adicional que se obtiene de otra fuente.

En este sentido, una forma de medir el impacto de los microcréditos consiste en evaluar el desempeño de las instituciones microfinancieras (IMF). Medir el éxito de las instituciones que otorgan este tipo de financiamientos y evaluar la tasa de recuperación de los créditos. La revolvencia de los empréstitos funge como un indicador del desempeño de acreditados e IMF.

Por lo que se refiere a las IMF, existe evidencia (Mansell, 1995; Yunus, 1998) de que las instituciones que emplean el ahorro como fuente principal de recursos tienen un mejor desempeño que las que sólo otorgan crédito, pues en el caso de estas últimas, sus fuentes son transferencias y donativos temporales que en cuanto se agotan, inevitablemente ponen en riesgo su viabilidad como instituciones.

En México se ha reconocido la existencia de los microcréditos como una fuente de financiamiento utilizada por distintos sectores. También se ha reconocido la falta de información y la escasa regulación como rezagos importantes en esta materia. La Ley de Ahorro y Crédito Popular y la creación del Banco Nacional de Servicios Financieros (Bansefi), en sustitución del Patro- 
nato del Ahorro Nacional, que datan del año 2001, son avances que apuntan hacia la regulación de este sector, cuyo crecimiento ha sido explosivo en los últimos diez años.

Las IMF (Conde, 2000) se han dedicado más a la práctica crediticia que a la documentación de experiencias, lo cual es natural si se considera que su negocio consiste en prestar y en algunos casos también captar los recursos de pequeños ahorradores. La labor de documentación de experiencias y diseño de metodologías de evaluación de impacto recae más en los analistas y donadores, que desean saber si las microfinanzas fungen con su cometido de generar crecimiento y reducir la pobreza.

Aunado a lo anterior, la inexistente regulación que había hasta junio de 2001, y que a la fecha persiste, desemboca en el problema informativo del que se ha hablado. En efecto, el problema de información se presenta en dos niveles: para las autoridades, que no saben exactamente qué están haciendo muchas de las IMF, especialmente las no reguladas, y para las IMF, que desconocen el uso que los acreditados y beneficiarios de este tipo de programas hacen de los recursos.

La importancia de estudiar el microcrédito obedece pues a por lo menos dos razones: primero, la necesidad existente de desarrollar una metodología que contribuya a evaluar el impacto de los microcréditos y, segundo, continuar con los aún incipientes avances documentales (destacan los trabajos de Mansell, 1995; Sckertchly, 2000 y Conde, 2000) que hay en la materia, de manera particular en México, donde hemos experimentado el escepticismo imperante entre profesionales de las ciencias sociales sobre este tema.

\section{Fundamentos teóricos del microcrédito: el problema de la información asimétrica}

La información asimétrica es un factor clave en el proceso de intermediación financiera. Existe información asimétrica cuando una de las partes no cuenta con información relevante sobre las características del prestatario. El acreedor no puede saber ' $a$ priori' si el acreditado utilizará los recursos en la forma acordada o bien, si los empleará para gasto de consumo (Bebczuk, 2000).

Este factor es un incentivo para que el deudor oportunista disfrace la naturaleza de un proyecto y aplique los recursos a un destino diferente al anunciado. Desde luego, este problema no 
existiría si el acreedor contara con información completa o con medios infalibles de detección y determinación de riegos.

Para combatir este problema, el acreedor endurece sus políticas o bien, sube la tasa de interés, con lo cual afecta a los deudores honestos. La dinámica del problema de la información asimétrica es la siguiente: el prestatario busca extraer un beneficio de la falta de información con que cuenta el acreedor; éste reacciona imponiendo una mayor tasa de interés, por lo que, en el equilibrio final, los deudores de buena calidad terminan subsidiando a los de baja calidad, con lo que se tiene un equilibrio pooling (Armendáriz y Morduch, 2000).

Tal es el planteamiento básico de la información asimétrica. No obstante, existen algunos factores adicionales que es necesario ponderar. Un supuesto importante del cual se parte, es que los individuos tienden a maximizar sus beneficios, dejando al margen la dimensión ética.

Por tanto, la información asimétrica altera el funcionamiento eficiente del mercado de crédito provocando, en un caso extremo, que como medida de protección, los acreedores interrumpan el crédito, dando lugar al racionamiento de crédito. Sin embargo, es más probable que el prestamista acuda al alza de tasas de interés como primera medida de protección mediante el incremento de lo que se denomina spread o margen de intermediación.

No obstante lo anterior, la elevada tasa de interés puede incidir negativamente en algunos proyectos cuya rentabilidad o beneficio esperado no alcanza a cubrir la tasa activa; es decir, la tasa que el intermediario financiero cobra por un crédito. Esto puede llevar a algunos prestatarios de bajo riesgo a alejarse del mercado de crédito, dando origen al mecanismo llamado selección adversa, que no es sino el efecto paradójico del incremento de tasas. ¿Quién está dispuesto a pagar un precio más alto? De acuerdo con esta teoría, lo harán aquellos acreditados que por su mala calidad sólo pueden acceder a empréstitos más caros.

En términos generales, la teoría establece tres perfiles de acreditados o inversionistas de acuerdo con la recurrencia de sus compromisos de deuda: conservadores, especulativos y arriesgados (Ponzi). Los acreditados que se encuentran financieramente cubiertos -conservadores- se definen como inversionistas que adquieren compromisos de pago menores a los ingresos esperados.

Los segundos, que se caracterizan por ser especulativos, adquieren compromisos de pago en un esquema donde, en promedio, la deuda ocasiona compromisos sincronizados con los in- 
gresos esperados, con excepción del primer periodo, cuando requieren las obligaciones exceden a los ingresos y, cuando requieren de financiamiento adicional para cubrir las amortizaciones de la deuda. Sin embargo, pasada esta fase generan ingresos suficientes para cubrir las obligaciones.

Finalmente, los acreditados denominados arriesgados, o Pon$z i$, se definen como aquellos inversionistas que necesitan de refinanciamiento no sólo para cubrir sus amortizaciones en la fase inicial, sino incluso para pagar los intereses.

Un mecanismo adicional con el que se cuenta para enviar señales de seguridad al acreedor es la garantía. Ésta constituye una señal efectiva de la seguridad de un proyecto. Más adelante veremos qué sucede cuando se carece de este factor de seguridad, como sucede con los microcréditos.

Veamos cómo funciona el elemento de la garantía en la determinación de la seguridad de un proyecto y su relación con el mecanismo de selección adversa.

Normalmente, las personas solicitan créditos con la expectativa de obtener un rendimiento o ganancia mediante la compra o ampliación de sus instalaciones productivas; esta ganancia debe ser superior a la tasa de interés vigente en el mercado y debe incluir, además, una cierta prima de riesgo a partir de que las ganancias son esperadas y anticipadas; es decir, no son valores ciertos sino esperados. En términos formales, esta idea quedaría representada de la siguiente manera:

$$
P=g^{*} K-\Psi^{*} K-r^{*} K>0
$$

Esta ecuación nos indica que la ganancia total esperada neta de intereses, que hemos simbolizado como $P$, debe ser positiva. Dicho en otras palabras, la ganancia total esperada $(g * K$, donde $g$ es la tasa de ganancia como proporción del capital fijo), deducido el riesgo en que se incurre por realizar la decisión de la compra de bienes de capital o de ampliación productiva (riesgo que hemos simbolizado como $\Psi^{\prime \prime} K$, donde $\Psi$ es la tasa de riesgo como proporción del capital), debe ser mayor que el monto de interés que podría obtenerse si esos recursos se hubieran destinado a la compra de activos financieros seguros. Este monto de interés está representado por $r^{*} K$, donde $r$ es la tasa de interés vigente.

A partir de esta idea se puede precisar la determinación del monto de recursos que el acreditado está dispuesto a solicitar para la compra de bienes de inversión. Éste puede establecerse a 
partir de la condición de maximización matemática de la función de la ganancia; esto es:

$$
\frac{d P}{d K}=0
$$

Aplicándolo a nuestra ecuación de ganancia total, obtenemos:

$$
\frac{d P}{d K}=g-\Psi-r=0
$$

Lo cual significa que: $g-\Psi=r$; es decir, el monto de recursos solicitados que se traducirá en inversión llegará al punto en que la tasa de ganancia esperada, menos la prima de riesgo, sea equivalente a la tasa de interés.

Podemos representar esta idea mediante el siguiente gráfico, en el cual hemos colocado, en el eje de las ordenadas, la tasa de ganancia $g$, la tasa de riesgo $\Psi$, y la tasa de interés $r$; mientras que en el eje de las abscisas está representado el monto de inversión:

\section{Gráfica I}

Tasa de ganancia y tasa de riesgo en crédito

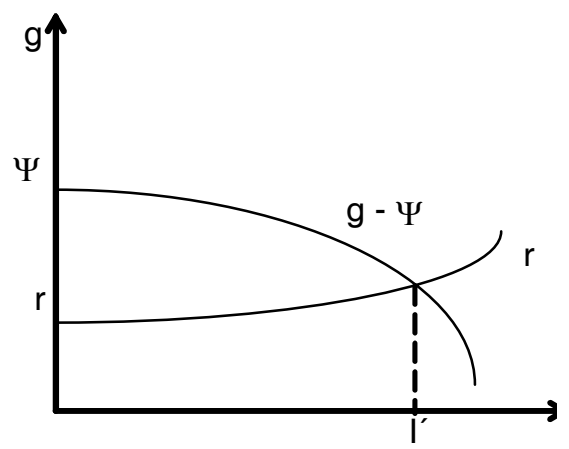

Fuente: Elaboración propia.

Una primera conclusión a este respecto, es que ninguno de los mecanismos que se han citado soluciona el problema de la información asimétrica, sólo consiguen aliviar algunas de sus consecuencias. Un instrumento adicional es el de la reputación o his- 
torial crediticio del prestatario; si mediante ese historial se demuestra que el solicitante ha cumplido favorablemente con sus compromisos, es muy probable que sea sujeto de crédito. Por el contrario, si el prestatario tiene una historia crediticia cuestionable, es altamente factible que los probables acreedores se muestren reacios a prestarle, o bien, que lo hagan a una tasa o costo muy elevado para él.

El resultado de la información asimétrica se traduce entonces en racionamiento de crédito, selección adversa y altas tasas de interés, tanto para proyectos seguros o prestatarios cumplidos como para los que no lo son. Sin embargo, existen mecanismos que ayudan a mitigar las consecuencias de la información asimétrica. Los bancos son instituciones especializadas que tienen elementos como el historial crediticio para comprobar la calidad de un prestatario (véase Freixas y Rochet, 1997, cap. 5).

Es importante señalar que los efectos de la información asimétrica también surgen respecto a los ahorristas, quienes son los acreedores de la banca. En este caso, las instituciones financieras, intermediarios, pasan de víctimas a victimarios, pues cuentan con información de la que carecen los depositantes. De ahí, la importancia de la supervisión prudencial que deben ejercer los gobiernos sobre las instituciones de crédito, ya sea en la forma de auditorías, regulaciones o reservas preventivas que deben generar los propios bancos para garantizar parte de sus operaciones.

La asimetría informativa adopta entonces cualquiera de las modalidades señaladas; recapitulando, diremos que son: selección adversa, cuando el acreedor no es capaz de distinguir entre proyectos con diferentes niveles de riesgo; riesgo ético, que es la habilidad del deudor para aplicar los fondos a un fin distinto al acordado con el acreedor, amparado en la falta de información con que éste cuenta, y finalmente, costos de monitoreo, que se vinculan con una acción oculta por parte del deudor para declarar ganancias inferiores. Estos últimos y el riesgo ético suceden una vez que se han entregado los recursos.

Cuando las llamadas fricciones informativas (Bebczuk, 2000) llegan a un extremo, se corre el riesgo de caer un racionamiento de crédito, donde el acreedor se excluye unilateralmente hasta de los proyectos más seguros. Un paso intermedio hacia esa medida es el incremento de la tasa de interés activa, con lo que el prestatario honesto termina subsidiando los proyectos más riesgosos. 


\section{Crecimiento económico, información asimétrica y sistema financiero}

El sistema financiero concentra los recursos de millones de ahorristas que tienen excedentes de liquidez y canaliza esos recursos hacia prestatarios que desean llevar a cabo proyectos para los que no cuentan con la totalidad o con una parte de los recursos.

La cualidad de un sistema financiero eficiente es que realiza las operaciones de intermediación que a los ahorristas les sería imposible llevar a cabo. Al hacerlo genera, mediante las economías de escala, un ahorro asociado a disminuciones de los costos de transacción y de información.

Los costos de transacción (Schettino, 2000) están ligados a la comunicación entre las partes y a la transferencia del dinero. Tienen que ver con los costos de analizar, administrar y evaluar un proyecto. Los costos de información incluyen las averiguaciones sobre el proyecto y sobre quién lo lleva a cabo, así como el monitoreo durante la vigencia del contrato.

Las economías de escala surgen cuando el costo unitario cae con la escala o volumen producido, en presencia de costos fijos, aquellos que no varían independientemente del volumen de producción, $v$. gr., renta, luz.

Supongamos un costo bancario fijo de $\$ 100.00$ por concepto de gastos de personal (administrativos), infraestructura edilicia y gastos de informática, y un costo variable de evaluación y monitoreo por acreditado de $\$ 10.00$. El costo unitario depende del número de préstamos del banco. Si éste hiciera un préstamo tenemos:

Costo unitario $=($ costo fijo + costo variable $) /$ número de préstamos

$$
C U=(100+10) / 1=110,
$$

Si el banco realizara dos préstamos tenemos:

$$
C U=(100+10) / 2=60
$$

Lo mismo sucede por el lado de las operaciones pasivas; es decir, de ahorro, donde el ahorrador funge como acreedor del banco. En presencia del sistema financiero, la sociedad ahorra por concepto de costos de transacción e información en los que tendría que incurrir cada ahorrador si prestara directamente. 
No obstante lo anterior, las microempresas, entendidas como pequeñas entidades de uno a 10 empleados, con o sin registro fiscal, difícilmente tienen capacidad de generar economías de escala. Peor aún, no generan economías de alcance, que consiste en la capacidad de una empresa para diversificar su producción.

La situación se agrava cuando esas empresas deben enfrentar marcos jurídicos que no están diseñados para propiciar la competencia económica sino que la dificultan y encarecen las transacciones; este aspecto fue demostrado por Hernando de Soto (1987) en su estudio empírico titulado El otro sendero. Si además deben afrontar altas tasas de interés, que es el castigo que la banca comercial impone por pertenecer a un sector poco competitivo y de alto riesgo, claramente se percibe la desventaja en que se encuentra este sector.

De acuerdo con Bebczuk (2000), una forma de mitigar los efectos de la información asimétrica es mediante la diversificación de la cartera de crédito.

Tenemos que el sistema financiero, por una parte, permite a la sociedad ahorrar, y, por la otra, disminuye el riesgo mediante la sofisticación de sus métodos de evaluación y la diversificación de su cartera. Existe, sin embargo, un riesgo adicional al propio de la operación de crédito: se trata del riesgo sistémico que implican las catástrofes naturales.

En la teoría del crecimiento económico, se trata de maximizar el bienestar de los habitantes con el incremento de la producción. Son tres los factores del crecimiento: el capital, la mano de obra y el progreso técnico.

La mano de obra aumenta tanto la producción como el número de habitantes; el producto per cápita se mueve en función del capital per cápita. El mismo volumen de capital puede generar distintos niveles de producción dependiendo de su productividad. El progreso técnico, a su vez, genera crecimiento con del uso de nuevos procesos de producción.

La importancia de estos factores en la teoría del crecimiento económico puede resumirse con el modelo de Solow (Romer, 2001). A grandes rasgos, el modelo de crecimiento de Solow muestra cómo el ahorro, el crecimiento de la población y el progreso tecnológico afectan el nivel de producción de una economía y su crecimiento con el paso del tiempo.

La oferta de bienes y la función de producción viene dada por: $Y$ $=F(K, L)$. Se supone que la función de producción mantiene rendimientos constantes a escala, por lo que se cumple: $z Y=F(z K, z L)$. 
Al dividir esta ecuación por la cantidad de trabajo $L$ disponible, obtendremos las unidades de producción por unidad de trabajo; nuestra nueva ecuación será: $y=f(k, 1)$. La pendiente de esta función de producción indicará cuánta producción adicional genera un trabajador con una unidad adicional de capital, o, en otras palabras, representará el producto marginal del capital, PMgK:

$$
\operatorname{PMgK}=f(k+1)-f(k)
$$

A su vez, la demanda de bienes procede del consumo y de la inversión; es decir, la producción por trabajador $(y)$ se divide entre el consumo por trabajador $(c)$ y la inversión por trabajador (i): $y=c+i$.

El modelo supone que todos los años la gente ahorra una proporción s de su renta y consume otra proporción $(1-s)$; esto es: $c=(1-s) y$

$$
0<s<1
$$

Sustituyendo nos queda: $y=(1-s) y+i{ }^{\circledR} i=s Y$, de lo cual se deduce que la inversión será igual al ahorro.

Con estos elementos, ahora podemos establecer que: $i=s f(k)$. Esta ecuación relaciona el stock de capital existente, $k$, con la acumulación de nuevo capital, i. En términos gráficos nos quedaría:

Gráfica II

Relación entre capital existente y acumulación

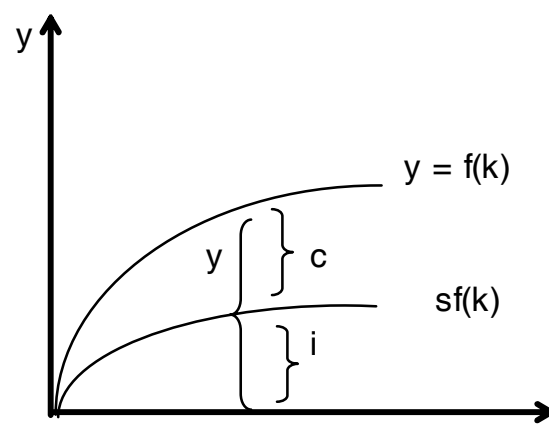


Para tomar en cuenta la depreciación en el modelo, suponemos que todos los años se desgasta una determinada proporción $\delta$, del stock de capital. Donde $d$ representa la tasa de depreciación, por lo que la cantidad de capital que se deprecia cada año será: $\delta^{*} K$.

La influencia de la inversión y de la depreciación en el stock de capital también puede ampliarse con las influencias de la tasa de crecimiento poblacional $(n)$; esta tasa altera la cantidad de capital por trabajador, ya que el crecimiento poblacional hace que disminuya el capital por trabajador. Finalmente se puede introducir un tercer elemento que influye en la tasa de acumulación de capital, derivada de la utilización del capital; es decir, la eficiencia del trabajo $(g)$. Este factor refleja los conocimientos de la sociedad sobre los métodos de producción: a medida que mejora la tecnología existente, la eficiencia del trabajo aumenta.

Reunidos todos estos elementos, podemos establecer que la ecuación que muestra la evolución de $k$ con el paso del tiempo es:

$$
\Delta k=s f(k)-(\delta+n+g) k
$$

Esta ecuación nos dice que, para mantener constante $k$, es necesario $\delta^{*} k$ para reponer el capital depreciado, es necesario $n^{*} k$ para proporcionar capital a los nuevos trabajadores, y es necesario $g^{*} k$ para proporcionar capital a los nuevos trabajadores efectivos creados por el progreso tecnológico. Todos estos elementos pueden resumirse en la gráfica III:

\section{Gráfica III}

\section{Acumulación de capital en estado estacionario}

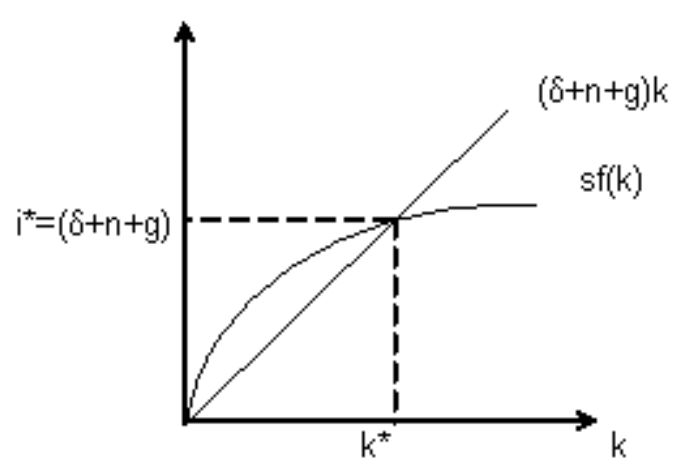

Fuente: Elaboración propia. 
En la gráfica III, $\mathrm{k}^{*}$ representa la acumulación de capital en el estado estacionario, y, de acuerdo con el modelo de Solow, esa acumulación sólo puede modificarse si existe un cambio tecnológico importante que obligue a un incremento en el nivel de inversión, y, en consecuencia, una modificación en la tasa de ahorro de la economía. De conformidad con lo anterior, la canalización de los niveles de ahorro hacia el sistema financiero será crucial para el crecimiento económico.

\section{Sistema financiero y crecimiento económico}

La relación del crecimiento económico con el sistema financiero se da de la siguiente forma: para aumentar la cantidad de capital físico y humano es necesario ahorrar una fracción del ingreso corriente y traducirlo en inversión (tal es el enfoque de la teoría neoclásica y su planteamiento del ahorro previo).

El sistema financiero permite establecer una conexión entre los individuos que gastan por debajo de su ingreso y los que lo hacen por encima de sus posibilidades. La responsabilidad del sistema financiero consiste en incrementar la cantidad y la calidad de la inversión.

En principio, se parte del hecho de que el ahorro es igual a la inversión. De este modo, tenemos que ingreso $(\mathrm{Y})=$ consumo (C) + inversión (I).

El ahorro es la diferencia entre el ingreso y el consumo. Tenemos entonces que: ingreso - consumo $=$ ahorro $=$ inversión. $\mathrm{Y}-$ $\mathrm{C}=\mathrm{S}=\mathrm{I}$.

La transformación del ahorro en inversión se logra mediante el sistema financiero que para lograr esa transformación incurre en gastos y costos de transacción, con lo que:

Inversión $=$ ahorro - costos de transacción e información .

Es debido a la existencia de economías de escala que el sistema financiero logra reducir estos costos, elevando la inversión y el crecimiento.

Existe evidencia empírica (Levine, 1998) que proporciona validez al planteamiento teórico que vincula el desarrollo financiero y el crecimiento económico. El resultado de análisis estadísticos y econométricos demuestra que el sistema financiero tiene influencia en el crecimiento de los países. Un indicador que da cuenta de ello es el del volumen de crédito a empresas no finan- 
cieras como porcentaje del producto interno bruto (РIB). Igualmente, un aumento de un punto porcentual en el volumen del crédito a esas empresas (Bebczuk, 2000:122) eleva la tasa de crecimiento anual en alrededor de un punto porcentual.

Si se compara el caso de un país subdesarrollado cuya relación crédito-producto es de 16\% con el de los países desarrollados, que ronda $25 \%$, y se hace una pequeña estimación, tenemos que de contar con una relación similar a la de un país desarrollado, la economía en desarrollo agregaría $1.1 \%$ a su tasa de crecimiento, la que, según los datos (Bebczuk, 2000), fue de sólo 1.8\% en el periodo 1960-1995.

Para apreciar la diferencia, veamos un ejemplo aritmético:

Supongamos que el PIB per cápita del país subdesarrollado es de $\$ 100.00$, creciendo a $1.8 \%$ anual. Al cabo de un año tenemos:

$100 * 1.018=101.8$. En el segundo año:

$101.8 * 1.011=102.9$. y en 20 años, el PIB per cápita habrá pasado a:

$100 * 1.08$ ^ $20=142.9$.

Ahora bien, si ese país gozara de un nivel de desarrollo financiero igual al del promedio de los países desarrollados, su tasa sería 1.8 $+1.1=2.9 \%$, y al cabo de 20 años, su PIB per cápita sería de $\$ 177.1$.

Hasta hace relativamente poco tiempo, muchos investigadores rechazaban la idea de que el sistema financiero fuera un motor del crecimiento económico. Sostenían que el crecimiento era función de las inversiones que se hicieran, no de cómo se las financiara. No fue sino hasta 1969, con los trabajos de Goldsmith, que se demostró la relación positiva entre el desarrollo financiero y el crecimiento económico (Hermes y Lensink, 1996: 7).

Con los estudios de Mckinnon (1973) se reconoció la relación entre el desarrollo de los mercados financieros y el crecimiento económico y se introdujo el análisis del tema en la agenda de los investigadores interesados en los países en desarrollo. Actualmente existe una idea muy difundida acerca de la participación del Sistema Financiero en el crecimiento económico. Las técnicas econométricas llevadas a cabo en los últimos 12 años validan esta interpretación.

Hemos visto cómo los problemas de información asimétrica inciden negativamente en el desarrollo del sistema financiero y 
en la configuración de una serie de costos asociados al problema. Por ello, los mecanismos para reducir la información asimétrica en las relaciones financieras constituyen el cimiento del sistema.

Cuanto más profundos sean los problemas informativos, más frágil es el sistema financiero y más proclive a una crisis. Las crisis financieras han afectado a diversos países (México 1995, Corea del Sur 1997, Argentina 2000), siendo más comunes y severas en los países en desarrollo. Una causa muy difundida, ha sido la falta de un cimiento informativo fuerte y un sistema financiero consolidado.

\section{Flujos internacionales de capitales}

El flujo externo de capitales es otro tópico asociado a los mecanismos de información asimétrica. La inversión nacional se financia originalmente con el ahorro nacional a través de la intermediación financiera. En una economía abierta, el ahorro extranjero puede complementar al ahorro interno. Los países en desarrollo tienen en teoría mejores oportunidades de inversión que los países desarrollados. Esto se debe a la productividad marginal decreciente y a que el ahorro es mayor en estos países.

Al existir una mayor abundancia de capital este se torna más barato dentro de estos países. A cambio, reciben una mayor tasa de interés en los países en desarrollo donde el capital es escaso. De esta manera, los países desarrollados obtienen un mayor beneficio al lograr un rendimiento más elevado para su ahorro. Esta diferencia entre ahorro e inversión se conoce en la contabilidad nacional como déficit o superávit de la cuenta corriente de la balanza de pagos (Herrera, 1987; Hernández Trillo, 2003).

El déficit de la cuenta corriente, tan común en países en vías de desarrollo se puede entender como el exceso de inversión sobre ahorro. Bien como exceso de gasto sobre producción nacional o como señala Schettino (2000) de demanda sobre oferta, lo que en economía cerrada conduciría a inflación pero que al contar con fronteras abiertas encontramos que ese diferencial se cubre con importaciones, que se traducen a su vez en una mayor oferta de productos, precios bajos y déficit de cuenta corriente.

La cuenta corriente es igual a las exportaciones menos las importaciones, menos pagos netos por servicios factoriales y no factoriales al exterior (intereses, turismo, utilidades, seguros, dividendos). 
$C C=X-M-N S$

Donde: $\mathrm{CC}=$ cuenta corriente, $\mathrm{X}=$ exportaciones, $\mathrm{M}=$ importaciones, $\mathrm{NS}=$ pagos netos por servicios al exterior.

Cuando $\mathrm{M}+\mathrm{NS}$ es mayor que $\mathrm{X}$, tenemos un déficit de la $\mathrm{CC}$, en cuyo caso debe equilibrarse con mayor endeudamiento o atracción de inversión extranjera, sea por vía directa o indirecta.

Este exceso de gasto sobre ingreso es igual que el exceso de inversión sobre ahorro. Es equivalente a PIB $=\mathrm{C}+\mathrm{I}+\mathrm{CC}$, donde: $\mathrm{C}=$ consumo, $\mathrm{I}=$ inversión.

Rescribiendo tenemos:

$$
\begin{aligned}
& S-I=X-M-N S \\
& S-I=C C
\end{aligned}
$$

Donde $\mathrm{S}=$ ahorro, $\mathrm{I}=$ inversión.

Cuando $S$ es mayor que I, tenemos un superávit de CC, indicando que el ingreso supera al gasto. Esta diferencia se destina a otros países que financian el déficit en CC con mayor inversión.

Cuatro factores marcan la importancia de los mercados financieros internacionales en los últimos años:

- Mayor integración financiera.

- Escalada de crisis cambiarias.

- Volatilidad financiera.

- Incapacidad de los argumentos económicos tradicionales para explicar los fenómenos actuales.

Hemos visto que el problema de la información asimétrica es fundamental. En el caso particular que nos ocupa, el de financiamiento de microcréditos, no existe una forma tradicional para que los deudores den señales de certeza sobre un proyecto, toda vez que no se cuenta con garantías reales y muy comúnmente tampoco existen antecedentes crediticios. Por ello, se hace necesario recurrir a otro tipo de explicaciones y respuestas al problema.

\section{Microcrédito}

En el caso de los microcréditos, es más difícil aún para el prestamista saber si el deudor aplicará el crédito en aquel proyecto que ha señalado o si lo utilizará para un fin distinto. Éste es un problema que la banca tradicional subsana elevando la tasa de inte- 
rés y realizando exhaustivas evaluaciones de crédito que pueden pagar sus clientes en virtud del tamaño de las operaciones. Sin embargo, en el caso de los microcréditos sería muy caro realizar evaluaciones individuales de cada solicitud de crédito, pues el costo de la investigación crediticia rebasaría incluso el tamaño del crédito (Esquivel, 2006a).

Además, la gran mayoría de las personas que componen este mercado no cuentan con referencias bancarias, antecedentes crediticios o referencias comerciales, por lo que además de costoso resulta imposible verificar y evaluar con los criterios tradicionales.

El mercado de los microcréditos resulta un caso muy claro en el que los acreedores trabajan con información asimétrica. ¿Cómo, entonces, las instituciones microfinancieras más conocidas han podido trabajar con índices de recuperación más altos que los de muchos bancos tradicionales? Para dar respuesta a esta pregunta debemos realizar un análisis de esta metodología de crédito.

\section{Microcréditos y pobreza}

Durante los últimos treinta años, ha surgido una metodología de crédito enfocada a la atención de grupos marginados sin experiencia crediticia y sin garantías reales. El microcrédito es un instrumento de financiación, o créditos en pequeña escala cuyos montos van de 60 a 600 dólares, en su mayoría, y que se destinan principalmente a mujeres en grado de pobreza y pobreza extrema.

Como se ha explicado exhaustivamente (Mansell, 1995; Conde, 2000; Ruiz Durán, 2002; Esquivel, 2006a), la metodología de microcrédito surgió formalmente en 1976, en Bangladesh, con el conocido Grameen Bank o banco del pueblo. Su director general y diseñador, Muhamad Yunus, un economista graduado en Estados Unidos y laureado en octubre de 2006 con el premio Nobel de la Paz, detectó que los pobres del medio rural y urbano son capaces de iniciar y mantener negocios pequeños siempre y cuando cuenten con el financiamiento necesario.

Su estrategia se convirtió en el mayor banco comercial dedicado a las microfinanzas. ${ }^{3}$ De haber iniciado otorgando crédito en

\footnotetext{
${ }^{3}$ En la actualidad existen muchas otras experiencias famosas que emplean la metodología de grupo solidario del Grameen Bank, o bien, una metodología diferente, como puede ser la de banco comunal que diseñó el Dr. John Hatch, fundador de la Foundation for Internacional Community Assistance. Algunas de esas instituciones son: la Association for Social Advancement (ASA), el Banco Rakyat de Indonesia (BRI), el Badan
} 
forma directa, hoy el Grameen Bank cuenta con más de mil sucursales y con más de 4 millones de acreditados, 94\% de los cuales, son mujeres, registrando un índice de recuperación de 98\%. ${ }^{4}$

\section{Microcrédito contra programas asistenciales}

El microcrédito es un enfoque heterodoxo, a diferencia de la visión tradicional, según la cual los pobres siempre lo serán y por tanto es necesario otorgarles un subsidio permanente, ya sea con un crédito barato o bien con transferencias directas.

El microcrédito postula que el pobre requiere financiamiento rápido y en condiciones de mercado. No porque así lo demande, sino porque la experiencia anterior demostró que una vez agotados los recursos iniciales, se agotaba el programa, dado que no había ninguna recuperación o ésta era insignificante comparada con los gastos operativos y de administración.

Los programas gubernamentales anteriores al enfoque de microcrédito basaban su estrategia en la promoción y el fomento de grandes bancos de desarrollo que canalizaban recursos en forma de subsidio (Robinson, 2001; Esquivel, 2006b). No tenían una estrategia definida para recuperar los recursos, además de que la tasa de interés que se cobraba, por debajo de la de mercado, introducía distorsiones en el proceso crediticio. Con lo que se llegaba a un círculo de crédito, escasa recuperación, y pérdida de patrimonio.

El enfoque de microcrédito introdujo al menos dos diferencias sustanciales: cobro de tasas de mercado e introducción de esquemas de ahorro; es decir, intermediación completa para los pobres, con lo que se obtenía un alto grado de compromiso por parte de los acreditados y, en segundo término, un elevado índice de recuperación.

\section{Estrategias de microcrédito}

Una limitante muy significativa para que la banca tradicional otorgue financiamiento a este segmento, es que los pobres no cuentan con antecedentes crediticios ni con garantías. Por ello, el Grameen

Kredit Kamata (BKK), el BRAC de Bangladesh, el BancoSol de Bolivia, o el recientemente autorizado banco Compartamos de México. Lo común entre ellas es su búsqueda de esquemas de sostenibilidad financiera. Véase Selvavinayagam (1995).

${ }^{4}$ En toda América Latina, el mercado atendido por todas las IMF no llega siquiera a la mitad de lo que atiende el GB, lo que evidencia el potencial de crecimiento que tenemos en este campo. 
Bank y otras instituciones como Accion International y Fundación Internacional para la Asistencia a las Comunidades, han diseñado metodologías específicas para la atención a los más pobres.

Existen tres enfoques principales utilizados por este tipo de instituciones: el grupo solidario, el banco comunal y el enfoque tradicional de crédito individual.

\subsection{Grupos solidarios}

El más conocido es el de grupos solidarios, metodología que fue diseñada por el Grameen Bank (Yunus, 1998) y que consiste en la formación de pequeños grupos de entre cinco y 10 personas que se garantizan mutuamente la operación del crédito. Cada miembro responde por el crédito de los otros integrantes; si uno de ellos incumple, los demás cubren su adeudo.

Los créditos no se otorgan en forma simultánea a todos los miembros del grupo; primero lo reciben los dos miembros más necesitados, y si cumplen estrictamente con las reglas del banco, entonces se le concede el crédito a otros dos, y así sucesivamente hasta completar todo el grupo.

Los créditos son montos pequeños, empleados principalmente para capital de trabajo, aunque en la metodología no está establecido que se deba destinar el crédito a un solo fin; es decir, cada miembro lo utiliza para desarrollar la actividad productiva que desee.

Dentro de este enfoque se considera como un componente muy importante el ahorro. En principio, éste es obligatorio, quedando cada miembro en destinar a un fondo común, $5 \%$ del monto recibido. Los plazos van hasta un año y las tasas de interés rondan $20 \%$ anual.

No existe más garantía que el aval social de todos los miembros del grupo, el cual no puede estar integrado por personas de distinto sexo ni por familiares, además de estar apegado a 16 reglas que el banco establece. Por ello, antes de recibir un crédito, cada grupo es introducido a la metodología y forma de trabajar del banco.

\subsection{El esquema de bancos comunales}

Cada banco comunal se compone de 30 a 50 miembros de una misma comunidad. Al igual que en el caso del enfoque de grupos solidarios, se trabaja con grupos de personas de un mismo sexo, 
preferentemente. Se nombra una junta de administración encargada de administrar el banco.

Una vez que el banco se ha constituido conforme a estatutos que los propios miembros establecen, recibe un monto de alguna institución de apoyo como la Agencia de los Estados Unidos para la Ayuda Internacional (USAID) o la Fundación Internacional de Ayuda a las Comunidades (FINCA). Se otorgan los recursos de acuerdo con los requerimientos individuales por un plazo de hasta un año. Son en su mayoría créditos para apoyo a capital de trabajo y la puesta en marcha de pequeños negocios.

Esta metodología fue diseñada por John Hatch en 1986 (Mansell, 1995). Es utilizada por FINCA, una organización civil encargada de brindar apoyo a comunidades, con sede en Virginia, Estados Unidos, y con una serie de oficinas en países en desarrollo como México.

Existe otra institución muy famosa en el mundo de los microcréditos: Acción Internacional, Estados Unidos, que es una ONG con sede en Massachussets, está ligada a diversas instituciones microfinancieras en el mundo, algunas de ellas graduadas como bancos comerciales. Tal es el caso del BancoSol, de Bolivia, que es la principal institución microfinanciera en ese país y el banco especializado en microcréditos más grande de América Latina.

En el mundo, existen instituciones de este tipo con carácter de bancos de desarrollo, como el Banco Rakyat de Indonesia (BRI) y el Badan Kredit Kamata (вкК). Este banco es la mayor institución de microcrédito de ese país. Su metodología es la de créditos individuales. Sin embargo, su característica más sobresaliente es que ha logrado algo que para toda institución microfinanciera es fundamental: la autonomía financiera y la sostenibilidad. Esto quiere decir que sus recursos, como los de cualquier banco sano, provienen de fuentes tradicionales: el ahorro y el reembolso de créditos con un interés competitivo.

Este interés debe ser suficiente para cubrir los costos de operación de dichas instituciones. Para lograrlo, además de cobrar tasas de mercado es indispensable abatir los costos operativos. Un banco con grandes oficinas, extenso personal administrativo y bajo grado de especialización, difícilmente podrá alcanzar la sostenibilidad, lo que en el largo plazo implica su desaparición, una vez que las fuentes gubernamentales o los subsidios internacionales se suspenden.

Precisamente, la gran lección del enfoque del microcrédito es que efectivamente ayuda a combatir la pobreza de los beneficia- 
rios y se constituye en una opción financieramente viable. De otro modo, la supuesta ayuda que proporciona a los que reciben un crédito de este tipo se convierte en una simple transferencia de recursos que a lo más alcanza a distorsionar el mercado, ofreciendo recursos a los que corrompen de algún modo la estructura de crédito o tienen algún contacto al interior de la organización que les permite recibir los recursos.

\subsection{Otras metodologías e instituciones de microcrédito}

Además de estos tres enfoques mencionados, existen otras muy extendidas que incluso trascienden a las instituciones microfinancieras: los fondos rotatorios, conocidos coloquialmente como tandas, fondos de garantía que son una valiosa herramienta cuando un acreditado requiere de mayores recursos que los que puede recibir de un programa de microcrédito.

Las uniones de crédito cuentan con una metodología propia basada en el ahorro forzoso de sus miembros. Estas instituciones atienden a sus socios, y generan con ello una relación arraigada y de largo plazo con cada uno de ellos.

Si bien se pueden encontrar más metodologías, las más características son las señaladas. Por lo que toca a las instituciones de microfinanzas, existen de todo tipo. Las más comunes son las ONG, pero son también las más limitadas, ya que al no estar reguladas por las instituciones de gobierno, no pueden legalmente atraer ahorro y por tanto reducen su función a la de crédito. También se encuentran en este espectro los bancos comerciales, como el propio Grameen Bank, el BancoSol o Compartamos, en México, así como bancos de desarrollo como el BRI y el BKK. Encontramos también asociaciones civiles como Santa Fe de Guanajuato, en México y Uniones de crédito y cooperativas. La característica común a todas ellas es que con distinto grado de éxito y de desarrollo, buscan lograr la viabilidad financiera para atender a un mayor número de pobres.

\section{Estructura de un banco especializado en microcrédito}

Uno de los graves problemas con el que se enfrentan muchas instituciones que esperan especializarse en microfinanzas, es que no dejan atrás viejas prácticas y terminan por combinar lo peor de dos mundos (Lacalle, 2002); a saber: una estructura burocratizada propia de los bancos de desarrollo, y esquemas de crédito 
y financiamiento de la banca comercial tradicional, que se enfocan a un mercado cualitativamente distinto al de los pobres. De este modo, tienen estructuras muy grandes, pesadas y con procesos lentos y métodos de evaluación de crédito que no responden a la dinámica de una institución microfinanciera.

El Grameen Bank tiene más de 1,400 sucursales que cubren casi todo el territorio de Bangladesh. Cada sucursal tiene autonomía de gestión y se encuentra descentralizada. Determina los créditos que otorga y sólo reporta periódicamente a una oficina de área que tiene a su cargo alrededor de quince sucursales. Existe una oficina regional responsable de varias oficinas de área arriba de la cual solo está la oficina central, que se encarga de la Dirección, el control de presupuestos, asesoría, evaluación, investigación y desarrollo de nuevas metodologías, formación de personal y relaciones públicas.

Se trata de integrar estructuras que respondan a los requerimientos de la población objetivo. Tal es el caso del modelo AsA, una organización famosa por su eficiencia en el control de costos y por su método estandarizado de crédito, lo que le ha permitido ofrecer financiamiento a tasas muy competitivas. Es común observar que las instituciones microfinancieras que no siguen un patrón de austeridad, y sobre todo de estructuras que se adapten a las características del mercado, fracasen sin remedio (Meehan, 2004).

Esto se debe a que cuando los recursos que provienen de fuentes externas se agotan y las IMF no han bajado significativamente sus gastos de operación y elevado sustancialmente la recuperación de créditos, la estructura se vuelve una carga que consume incluso los recursos que originalmente se habían destinado al crédito. Ésta es una situación que se vive en diversas instituciones en México, algunas de ellas gubernamentales y otras privadas que no se autorregulan.

\section{Panorama actual de las instituciones microfinancieras}

La mayoría de las IMF se especializan en el crédito a la mujer, por diversas razones, algunas de carácter ético, pero las más importantes son de carácter económico, toda vez que el criterio que prevalece ante cualquier organismo es el de la eficiencia y la maximización del beneficio.

Se ha comprobado que las mujeres utilizan, en un mayor porcentaje, los recursos prestados en actividades que repercuten en 
el mejoramiento del nivel de vida de los hogares. Al mismo tiempo, la evidencia demuestra que la tasa de recuperación de los créditos a mujeres es más elevada que la de los hombres (Yunus, 1998; Conde, 2000). Las razones de carácter humanitario destacan la desventaja que tiene la mujer en el medio social frente al hombre, dando por resultado que no tenga las mismas oportunidades de acceder a un trabajo remunerado.

\section{Algunas críticas al enfoque de microcréditos}

Las principales críticas que se han hecho al enfoque del microcrédito señalan que éste tiene mucho de idílico. No existe aún evidencia empírica suficiente para determinar si el microcrédito incide favorablemente y de forma determinante en el mejoramiento del nivel y calidad de vida de las personas. No obstante, muchos de los estudios hechos hasta ahora sugieren que es así.

La evidencia muestra que en un nivel microeconómico, los microcréditos coadyuvan a mejorar las condiciones de las personas y los pequeños negocios que se han beneficiado de ellos. No obstante, en un nivel macro existe un escepticismo muy generalizado aún sobre la incidencia del microcrédito en el desarrollo y el crecimiento. Debemos insistir que mucho de ello se debe a que este instrumento crediticio es aún muy reciente como para contar con datos suficientes que permitan validar la información.

Lo que también se ha demostrado en los estudios de impacto es que las familias que se han beneficiado de microcréditos han mejorado su nivel de vida en comparación con aquellas que no lo han hecho. No obstante, esta información se considera sesgada, toda vez que no se basa en selecciones aleatorias de los grupos analizados, llamados de control y de intervención.

Finalmente, para acceder a evidencia empírica y estadística suficiente que permitiera evaluar el impacto macroeconómico del microcrédito, se requeriría de series de tiempo muy largas, de entre 30 y 50 años, de las que todavía no se dispone (Hulme y Mosley, 1996).

No obstante, los logros de este enfoque comienzan a observarse, sobre todo con la viabilidad de las instituciones que lo practican, con la inserción de nuevos actores en el sistema financiero y con la mayor penetración que se tiene, fundamentalmente en sectores sociales anteriormente soslayados por el sistema financiero tradicional. 


\section{Conclusiones}

Se ha destacado la importancia del microcrédito como un instrumento que han empleado gobiernos, instituciones privadas, bancos comerciales, ONG, uniones de crédito, cajas de ahorro y crédito popular, asociaciones civiles, etc., con el objetivo inicial de combatir la pobreza de los grupos de apoyo.

Originalmente, los microcréditos surgieron de manera práctica, durante los años setenta y ante el fracaso evidente del modelo anterior, basado en el crédito subsidiado, principalmente por medio de bancos de desarrollo. Esa metodología se fundamentaba en la idea de que allegando recursos a mayor número de agentes, se combatía la pobreza. Sin embargo, la introducción de esquemas subisidiados bajaba artificialmente las tasas de interés, lo que por un lado fomentaba el acceso a estos esquemas crediticios a grupos que no lo requerían pero que encontraban una oportunidad para allegarse recursos baratos, y, por otro lado, otorgaba a las instituciones pocos incentivos para alcanzar la eficiencia.

Fue en ese contexto que surgió esta nueva metodología, considerando además como elemento adicional a la eficiencia operativa, el combate a la pobreza. El microcrédito surgió de la práctica académica del profesor Yunus, "el pensamiento es acción", parafraseando a Nietzsche. En principio, el microcrédito fue una acción en respuesta a la labor que venían realizando los bancos de desarrollo que dependen de los recursos fiscales que canalizan los gobiernos. El microcrédito o, más ampliamente, las microfinanzas, incorporan además el ahorro como fuente de recursos para financiar las operaciones de las IMF.

En México, la práctica del esquema subsidiado ha tenido un sonado fracaso que se difundió en 1995 ante la crisis financiera. Si bien el microcrédito ya existía aún antes de esa fecha, era poco conocido, de lo que da cuenta Mansell en su texto Las finanzas populares en México (1995), donde realizó una recopilación de las principales metodologías sobre microfinanzas y puso a discusión un tema totalmente relegado hasta entonces. El libro en cuestión es más famoso hoy que cuando se publicó, pues salvo un pequeño grupo de interesados en la materia, pasó desapercibido.

Lo mismo sucede con el Grameen Bank, que hace seis años era una institución totalmente desconocida en México. Hoy es referente obligado para cualquier institución financiera, fideicomiso o gobierno, en sus tres niveles, que pretenda desarrollar un esquema similar. No obstante, el Grameen Bank nació en 1976 y 
Acción International existe desde los años sesenta, aunque no como institución microfinanciera sino filantrópica.

El resultado hasta hoy es que la filantropía y la banca de desarrollo están cediendo más terreno al microcrédito. Las razones son, primero, que el fundamento de estas dos opciones consiste en el otorgamiento de recursos a fondo perdido, lo que en palabras de Yunus se traduce del siguiente modo: "la caridad no resuelve el problema, sostiene la pobreza". En contradicción con esa postura, la metodología del microcrédito se basa en el fondeo de las operaciones de crédito con ahorro principalmente, con el fin de garantizar, en el largo plazo, viabilidad a las instituciones de microcrédito.

En segundo término, las IMF deben otorgar financiamiento con tasas de mercado que permitan cubrir el costo financiero y los gastos de operación. Además de apegarse a otras normas establecidas como: respetar el enfoque de género, es decir, grupos de hombres o grupos de mujeres, pero no grupos mixtos. Los montos no deben exceder la capacidad de pago de los acreditados, los plazos deben ser cortos y debe respetarse la metodología, sea individual, de grupo solidario o de banco comunal.

El éxito de las IMF depende de tres factores básicos:

- El índice de dependencia de los subsidios; éste toma valores entre cero y cien, siendo cero total independencia y cien indicando que habría que subir las tasas en 100\% para no depender de fuentes exógenas (Yaron, 1994).

- La cobertura de un programa de microcréditos debe ser amplia (miles de créditos) para abatir costos unitarios, suponiendo que tenemos costos fijos, para así generar economías de escala.

- El impacto del programa es el tercer factor; indica qué tan benéfico resulta el programa a los beneficiarios en términos de su calidad de vida; dicho de otra forma, si un programa de microcréditos no redunda en un mejoramiento de las condiciones de vida de la gente, aun cuando ésta siga por debajo de la línea de pobreza, entonces el programa no está funcionando.

Brevemente explicaremos esto último: de acuerdo con algunos teóricos de la pobreza (Boltvinik y Hernández Laos, 1999), existen tres elementos que miden la pobreza; a saber: la incidencia, que mide la cantidad de pobres; la intensidad, que mide qué tan 
pobres son los pobres, y finalmente, el tercer elemento -que introdujo el premio Nobel de Economía 1998, Amartya Sen, quien en 1976 publicó su famoso artículo "Poverty: An Ordinal Approach to Measurement", en el que desarrolló un nuevo índice para expresar la situación agregada de la pobreza en una sociedad-, conocido como el Índice de Sen, que incorpora la distribución del ingreso entre los pobres.

De este modo se explica por qué es benéfico para los pobres recibir un microcrédito que les permita mejorar su situación de vida aun cuando sigan estando por debajo de esa línea de pobreza. Por otra parte, los esquemas tradicionales han sido incapaces de abatir el rezago en esta materia.

En el estudio del microcrédito se deben considerar algunas ventajas y desventajas. Sobre las primeras, puede decirse que este enfoque es un campo aún novedoso, por lo que casi cualquier veta que se toque presenta información fresca, desconocida incluso para los versados en cuestiones financieras. Esto se debe en parte al escepticismo con que se mira, pero también a una cuestión temporal.

A pesar de ello, su estudio presenta serias desventajas: como dijimos, no existe información oficial y pública que nos dé señales sobre el comportamiento de este esquema de financiamiento. No tenemos información cuya consulta permita ver el impacto de los microcréditos a lo largo de 30 o 40 años, pues ese esquema de crédito es muy reciente. Tampoco contamos con análisis que determinen el comportamiento de las instituciones microfinancieras en el largo plazo. En este sentido, existe una gran dispersión del sector, tanto por el tipo de figura legal que adoptan y la ley o regulación a la que se someten, como en cuanto a su organización.

En México contamos con un sector de banca social en donde participan IMF en el sentido que hemos dado a esa definición en este artículo, como uniones de crédito, bancos, ONG o cajas de ahorro y crédito popular, que no necesariamente hacen microfinanzas; es decir, que no tienen entre sus objetivos combatir la pobreza o 'bancarizar' a los más pobres para que mejoren sus situación financiera al acceder a fuentes de financiamiento para sus proyectos de inversión. Se incluye en el sector a las organizaciones por los montos de sus financiamientos, tanto a instituciones que otorgan crédito al consumo como a aquellas que fomentan la superación de la pobreza.

A la fecha, sólo contamos con datos y estudios aislados que nos indican en qué medida han mejorado su situación las fami- 
lias que han recibido microcréditos respecto a las que no los han recibido. Sin embargo, son análisis sesgados, pues no se consideran muestras aleatorias.

No obstante, algunos estudios más serios (Khandker, 1998), principalmente del Grupo Consultivo de Asistencia a los más Pobres (CGAP), del Banco Mundial o del Programa de Naciones Unidas para el Desarrollo (PNUD), concluyen que el microcrédito ha tenido excelentes resultados. Así lo confirman también los datos que proporciona Acción International, o los de instituciones como la Sociedad Financiera Popular, Fincomún, el banco Compartamos, en México, los bancos comerciales como BancoSol en Bolivia, o bancos de desarrollo como el Banco Rakyat de Indonesia, que incluyen el ahorro como la parte complementaria del crédito, o bien la Asociación Civil Santa Fe de Guanajuato (Skertchly, 2000).

También existen casos en que la mala aplicación del enfoque del microcrédito hace fracasar al programa, lo cual no se debe al enfoque sino a la ejecución. En estos casos hablaríamos más de políticas públicas fallidas que de metodologías inviables. Estas experiencias son hasta ahora bastante malas, pues generalmente las ansias por obtener resultados rápidos, han dado paso a un espejismo y a programas de corte asistencialista y clientelar.

Por último, no podemos menos que reconocer lo que se señaló en otras secciones. Los programas de microcrédito que han sido evaluados, demostraron efectos positivos a nivel del ingreso y bienestar de las familias. Sin embargo, la evidencia para determinar su impacto en el nivel macroeconómico es todavía insuficiente.

\section{Bibliografía}

Armendariz-de Aghion, Beatriz y Jonathan, Morduch (2000), "Microfinance Beyond Group Lending", Economic of Transition, vol. 8, núm. 2, pp. 401-420.

Bebczuk, Ricardo, N. (2000), Información asimétrica en mercados financieros, Cambridge University Press, Reino Unido.

Boltvinik, Julio y Enrique Hernández-Laos (1999), Pobreza y distribución del ingreso en México, Siglo xxI editores, México.

Conde-Bonfil, Carola (2000), ¿̇ueden ahorrar los pobres?, El Colegio Mexiquense, México. 
Consultative Group to Assist the Poorest (2006), Principios clave de las microfinanzas, www.cgap.org.

De Soto, Hernando (1987), El otro sendero: la revolución invisible en el tercer mundo, Editorial Sudamericana, Buenos Aires.

Diario Oficial de la Federación (2001), Ley de Ahorro y Crédito Popular, México, junio.

Esquivel-Martínez, E. Horacio (2006a), "Microcrédito vs. pobreza", Ejecutivos de Finanzas, num. 3806, febrero.

Esquivel-Martínez, E. Horacio (2006b), “Las microfinanzas como respuesta para reducir la información asimétrica: el caso de la Ciudad de México", Comercio Exterior, (56) 8: pp. 658-672.

Freixas, Xavier y Jean-Charles, Rochet (1997), Microeconomics of Banking, MIT Press, Cambridge, Mass.

Grameen Bank, www.citechco.net/grameen/comunications/ index.htm

Hermes, Niels y Robert Lensink (1996), Financial Develpment and Economic Growth, Routledge Studies, Reino Unido.

Hernández-Trillo, Fausto (2003), Economía de la deuda, FCE, México.

Herrera-Nuñez, Manuel (1987), Metodología de la balanza de pagos, unAm, México.

Hulme, David y Mosley, Paul (1996), Finance Against Poverty, Routledge, Londres.

Khandker, Shahidur R. (1998), Fighting Poverty with Microcredit, Oxford University Press, Reino Unido.

Lacalle-Calderón, Maricruz (2002), Microcréditos, de pobres a microempresarios, Ariel, Barcelona. 
Levine, Ross (1998), “The Legal Environment, Banks, and LongRun Economic Growth”, Journal of Money, Credit and Banking, Agosto, 30 (3): 596-613.

Mansell Carstens, Catherine (1995), Las finanzas populares en México, cemla, México.

Mckinnon, Ronald (1973), Money and Capital in Economic Development, The Brookings Institution, Washington, D.C.

Meehan, Jennifer (2004), Tapping Financial Markets for Microfinance, Grameen Foundation UsA, Publications Series.

Robinson, Marguerite (2001), The Microfinance Revolution, Sustainable Finance for the Poor, The World Bank-Open Society Institute, Washington, $D C$ y Nueva York.

Romer, David (2001), Advanced Macroeconomics, McGraw Hill, Nueva York.

Ruiz-Durán, Clemente (2002), Microfinanzas, mejores prácticas a nivel nacional e internacional, UNAM, México.

Schettino, Macario (2000), "Economía informal”, El Universal. México, 1 de septiembre.

Selvavinayagam, K. (1995), Improving Rural Financial Markets for Developing Microenterprises, FAO Investment Centre Occasional Paper Series, núm. 2.

Sen, Amartya (1976), "Poverty: An Ordinal Approach to Measurement”, en Econometrica, vol. 44, núm. 2, marzo, pp. 219-231.

Skertchly, W. Ricardo (2000), Microempresa, financiamiento y desarrollo: el caso de México, Miguel Ángel Porrúa, México.

Stiglitz, Joseph y Andrew Weiss (1981), "Credit Rationing in Markets with Imperfect Information", American Economic Review, 71 (3): 393-410. 
Yaron, Jacob (1994), "Successful Rural Finance Institutions", Finance y Development, marzo.

Yunus, Muhammad (1998), Hacia un mundo sin pobreza, Andrés Bello Editores, Madrid.

Recibido: 20 de septiembre de 2005 Aceptado: 13 de septiembre de 2006

Horacio Esquivel-Martínez es candidato a Doctor en Economía por la Universidad Nacional Autónoma de México. Maestro en Administración Pública por el Instituto Nacional de Administración Pública, graduado con Mención Honorífica. Licenciado en Economía por la Universidad Autónoma Metropolitana. Cursó los diplomados en Estadística Aplicada en el Instituto Tecnológico Autónomo de México y de Banca y Finanzas en el Instituto Tecnológico de Estudios Superiores de Monterrey. Entre sus cursos sobre materias financieras y de promoción de productos y servicios bancarios destaca: "Impact assessment and client satisfaction" del Microenterprise Development Institute de la Southern New Hampshire University. Participó dentro la Tesorería del Gobierno del DF, como Asesor del C. Tesorero del DF y del C. Secretario de Finanzas. Laboró en el Fideicomiso de Administración de Cartera donde desarrolló diversas propuestas sobre Microfinanzas, Microcrédito y Banca Social con base en tres enfoques: sustentabilidad financiera, control interno y profesionalización de la planta laboral. Es catedrático de la Southern New Hampshire University en Manchester NH, Eu, donde ha impartido el curso "Trade and Globalization and its impact on women and the poor" dentro del programa de maestría en Community Economic Development. También ha sido asistente del profesor Dr. Carter Garber dentro del Microenterprise Development Institute de la misma universidad. En México ha impartido las materias de política económica, comercio internacional, evaluación de proyectos y computación aplicada a la economía. Habiendo sido profesor de la Universidad Tecnológica de México entre otras. 
Ulises Hernández-Ramos es estudiante del programa de Doctorado en Economía de El Colegio de México, maestro en Economía por la UNAM y licenciado en Economía por la misma universidad. Dentro de su experiencia laboral, ha sido profesor asistente en la Universidad Nacional Autónoma de México, profesor titular de Economía en la Universidad Tecnológica de México y asistente de investigador con especialidad en Econometría. 